\title{
Tuberculosis mortality and recent childbirth: a retrospective case-control study of Gibraltarian women, 1874-1884
}

\author{
Stacie D.A. Burke ${ }^{\mathrm{a}, *}$, Lawrence A. Sawchuk ${ }^{\mathrm{b}}$ \\ a Department of Anthropology, McMaster University, 1280 Main Street West, Hamilton, Ont., Canada L8S 4L9 \\ ${ }^{\mathrm{b}}$ Department of Anthropology, University of Toronto, Scarborough, 1265 Military Trail, Scarborough, Ont., Canada M1C 1 A4
}

\begin{abstract}
Prior to the introduction of effective treatment for pulmonary tuberculosis, there was little consensus on the potential health risk of pregnancy among infected women. While, intuitively, pregnancy was viewed as a risk for tuberculosis disease and mortality, early studies could not establish such a link with any great certainty. Our case study combines the methods of family reconstitution and a case-control approach to explore the possibility that the physiological and social strains of recent childbirth and the early mothering of infants may have been risk factors in adult female tuberculosis mortality in late 19th-century Gibraltar. The study is based on 244 reproductive age women who died between 1874 and 1884 ; some $55 \%$ of these deaths were attributed to tuberculosis. The record linkage indicates that almost $12 \%$ of the women who died had given birth within the year preceding their death. Factoring in the effects of age at death, marital status, and religion, the logistic regression results indicate that recent childbirth did not increase the risk of tuberculosis mortality among these women. (C) 2002 Elsevier Science Ltd. All rights reserved.
\end{abstract}

Keywords: Tuberculosis; Childbirth; Pregnancy; Mortality; Gibraltar

\section{Introduction}

Prior to the introduction of effective treatment for pulmonary tuberculosis (TB), there was little consensus on the potential health risk of pregnancy among infected women (Hamadeh \& Glassroth, 1992; Hedvall, 1953; de March, 1975; Snider, 1984; Wilson, Thelin, \& Dilts, 1973). While, intuitively, pregnancy was viewed as a risk for tuberculosis disease and mortality, early studies could not establish such a link with any great certainty. The following case study of tuberculosis in the British Mediterranean garrison town of Gibraltar focuses specifically on the issue of whether recent childbirth complicated or reactivated underlying tuberculosis infection in the 19th-century heyday of the great "white plague". A fundamental design element of this research is the use of the case study approach. This approach targets a single focal community to examine basic

\footnotetext{
*Corresponding author. Tel.: + 1-905-525-9140x27025; fax: + 1-905-522-5993.

E-mail address: sburke@mcmaster.ca (S.D.A. Burke).
}

principles through situating members of that community within their socio-cultural and ecological context. In evaluating the potential effects of recent childbirth, the study is somewhat opportunistically positioned in the 19 th century since tuberculosis was widespread, with high levels of infection and disease, ${ }^{1}$ and represented the single most predominant threat to adult survival. Unlike more contemporary studies (Espinal, Reingold, \& Lavandera, 1996; de March, 1975), the complete absence of any effective medical interventions makes it unlikely

\footnotetext{
${ }^{1}$ Especially in the case of tuberculosis, infection and disease represent very different physiological states. Infection is not necessarily equated with disease, so long as the body is able to contain $M$. tuberculosis bacilli successfully. Disease may manifest soon after infection, years after infection, or may never surface at all (see Starke, 1997; Ryan, 1993). Additionally, individuals could recover from tuberculosis disease though, from a historic perspective, de March (1975, p. 802) notes that tuberculosis was dubbed "the disease most likely to relapse".
} 
that any elevated risk of tuberculosis due to pregnancy and the immediate post-partum period will be masked.

In this study, we examine all deaths among reproductive age women in Gibraltar between the years 1874 and 1884 . We find that women who had given birth within one to two years preceding their deaths were not significantly more likely to die of tuberculosis than women who had not been recently confined. Since our analysis adopts a multivariate approach, we are able to factor in the effects of age, marital status, and religion when gauging the relative significance of recent childbirth on pulmonary tuberculosis mortality.

\section{Early and contemporary views on childbearing and tuberculosis}

The interest in the relationship between childbearing and tuberculosis mortality among women has a long history beginning with Hippocrates and Galen who "believed that pregnancy had a beneficial effect on tuberculosis" as the pressure exerted by an enlarging uterus led to the collapse of open cavities in the lungs (Snider, 1984, p. 10S). It is believed that by about the mid-19th century pregnancy came to be perceived as a deleterious influence on the progression of tubercular illness and that this perception more or less held until the introduction of effective treatment. Smith (1988, p. 163) cites the work of 1930s researchers who felt that "weak, malnourished consumptives already had a bad prognosis" and that the imposed burdens of pregnancy, the strain of labor, and the sudden fall of the diaphragm after delivery might fuel a reactivation of the disease and increase the risk of death. Snider (1984, p. 10S) adds that "rapid hormonal changes, the nutritional strains of lactation, and insufficient sleep from the time demands of a newborn infant" were all argued to increase the risk of TB activation in the first post-partum year. Anderson (1997, p. 330) notes that "in the early 1900s, women with TB were frequently treated with induced abortion to prevent the serious consequences of TB in pregnancy", and that this view of pregnancy as adversary among tuberculous women persisted well into the 1900s. In his work examining the rise of therapeutic sterilization in the early 20th century, Lerner (1994, p. 364) argues that "the most common indications were for conditions that potentially threatened the lives of pregnant women: previous Caesarean sections, chronic nephritis, heart disease, and tuberculosis". Furthermore, according to Lerner (1994, p. 373), physicians also tended to believe that tuberculous women gave rise to children "of poor stock", characterized by "low vitality", "tuberculous toxemia", and "physiological poverty".

Concerns over the risks associated with pregnancy and tuberculosis began to diminish substantially following the advent of effective chemotherapy. Even so, in the 1950s, Rosenbach and Gangemi (1956, p. 1035) revealed that "there is still much doubt in the minds of many practicing physicians as to what advice to give to these mothers with active or inactive tuberculosis as to the desirability of pregnancy during or after an active process". In their study based on over 30 years in a large tuberculosis clinic spanning the years 1925-1954, the authors concluded that "the progression of tuberculosis during pregnancy is a factor not of the pregnancy per se but of the tendency of the tuberculosis itself to progress" and that, furthermore, with more modern methods of treatment, "pregnancy should rarely be accompanied by any unfavorable progression of disease" (Rosenbach \& Gangemi, 1956, p. 1037).

In the 1970s perceptions of risk continued to advocate a cautionary approach in the management of pregnancies among Mycobacterium tuberculosis positive women, "... it seems reasonable to recommend that the condition of patients who have had tuberculosis should be carefully evaluated when pregnancy is discovered and, if any doubt exists, chemotherapy for tuberculosis should be administered, particularly toward the end of pregnancy..." (Edsall, Collins, \& Gray, 1970, p. 735). While "the controversy concerning the effect of pregnancy or the post-partum period on tuberculosis has lost most of its importance with the advent of effective chemotherapy" (Starke, 1997, p. 112), studies now focus on elucidating the necessity and timing of administering antituberculous drugs and addressing any potential risks of toxicity to mother and fetus (Good, Iseman, Davidson, Lakshminarayan, \& Sahn, 1981; Miller \& Miller, 1996; Schaefer, Zervoudakis, Fuchs, \& David, 1975; Starke, 1997).

According to Diwan and Thorson (1999), the potential effects of pregnancy on tuberculosis has, by far, commanded the most enduring attention in examining risk factors for tuberculosis disease and mortality among women. This focus has reinforced "the traditional view of women as merely vectors for childbearing and caring", while neglecting other areas of women's lives which might increase their risks of tuberculosis morbidity and mortality (Diwan \& Thorson, 1999, p. 1000). Increasingly and more generally, tuberculosis is becoming perceived as a gendered disease, where understanding general risk factors moves beyond such obvious effects as pregnancy to consider the larger physiological and social/cultural realities distinguishing women and men. ${ }^{2}$ The resurgence of TB in westernized countries has led to a reevaluation of many other factors involved in the expression of this disease (DeRiemer, Chin, Schecter, \& Reingold, 1998; Dolin, Raviglione, \& Kochi, 1994; Elender, Bentham, \& Langford, 1998; Raviglione, Sudre, \& Rieder, 1993). Like any number of

\footnotetext{
${ }^{2}$ See an alternate viewpoint offered by Walker and Cook (1998).
} 
infectious diseases, susceptibility to TB infection and active tubercular disease is likely influenced by both genetic and environmental factors (Blackwell, 1998; Bloom \& Small, 1998; Mizrahi, 1997; Pospelov, Matrakshin, \& Chernousova, 1996; Skamene, 1989). Environmental factors that have been associated with high rates of tuberculosis in historic populations include high population densities, substandard working conditions, and a general poverty-related dampening of the quality of life indicated by poor housing, inadequate and polluted water supplies, deficient sewerage and wasteremoval systems, improper and insufficient diets, and poor education. Individually, each of these factors could contribute to increased susceptibility to infectious disease; collectively, these factors presented an open invitation to the great intruder-the bacillus $M$. tuberculosis. The gendered perspective on tuberculosis argues that all factors must be considered when addressing the complexities of infection, the rate of progression from infection to disease, and from disease to mortality (Diwan \& Thorson, 1999; Hudelson, 1996; Mitchinson, 1991).

\section{Nineteenth-century Gibraltar: a case study and case- control approach}

\section{The community and ecological setting}

The focus of this investigation is the Rock of Gibraltar and, in particular, the civilian residents of this British crown colony in the 19th century (Fig. 1). Initially staking its importance as a strategic military station guarding the western entrance of the Mediterranean, Gibraltar quickly grew into a lucrative free port and mercantile hub. Owing to its small geographic size (approximately $4 \mathrm{~km}$ in length and a varying width of $0.32-1.21 \mathrm{~km}$ ) and its largely inhospitable terrain, most Gibraltarians lived crowded together in the town/ military garrison located on the western shores of the Rock. Writing in the 19th century, Sayer (1865) suggested that the high mortality rate characterizing the population stemmed from either "local causes of disease or unhealthy atmospheric influences", and the "almost total absence of sanitary precautions" since England's Public Health Act did not extend to Gibraltar.

Gibraltar's notoriously congested late-19th-century urban landscape, accommodating some 18,000 civilians and 5000 military within the walled town $(<0.40$ of a square kilometer in size), eased the spread of infectious diseases not only through high population density, but also through the communal experience of patio (or apartment-style) living. Residence within multi-household buildings and the sharing of resources brought people in close proximity of one another thereby increasing the probability of the transmission of airborne infections. The 1878 census rolls for Gibraltar indicate that some $25 \%$ of households were composed of either extended or multiple family units and that the majority of those living in Gibraltar were forced to occupy small, typically one-room, apartments (Sawchuk, 1993). The "evil habit of promiscuous spitting"3 (Horrocks, 1904), coughing, sneezing, and even forceful speaking were day-to-day events involved in the transmission of infectious microbes. "Overcrowding in close damp rooms" (Stokes, 1880) and "the unsanitary and sometimes fatal custom of keeping all windows and ventilating apertures of sick rooms rigidly closed" (Medical Officer of Health, 1893) aided further the spread of air-borne diseases like tuberculosis. At that time, the overcrowded, damp, dark, and poorly ventilated home environment would have been the primary environment for most adult Gibraltarian women.

Housing conditions were so dismal that one local physician admitted an "open street is much more desirable...than many of the lodgings of the lower orders of the inhabitants of Gibraltar" (Hennen, 1830). Danino's Patio, where 243 working class people lived cramped together in two row-style buildings, bore tremendous scrutiny in this respect. Doors and windows of this patio opened onto a wash-house, dustbins, latrines, and a large mule stable. Rooms were equipped with open charcoal fire places for cooking and heating purposes. Basins and handwashing stands in each room served as the sole means of bathing. Only seven latrines were available to accommodate the needs of this large patio. Potable water facilities consisted of a single cistern, capable of holding only 8994 gallons and, if filled, it was meant to serve the needs of 42 households. There was an average 5.2 persons per room in Danino's Patio, affording each occupant roughly 370 cubic feet of living space.

If, according to traditional gender roles, women's needs fell behind those of men and children in the household, their nutritional intake may have suffered. Poor nutrition can have serious epidemiological consequences for, as Balasubramanian, Wiegeshaus, and Smith (1994) suggest, in addition to lowering resistance to primary pulmonary tuberculosis, malnutrition may also lead to disease reactivation or an increased risk of reinfection. More particularly, recent experimental work by McMurray (1998) indicates that chronic proteindeficiency has specific detrimental consequences for tuberculosis resistance.

Quantitative estimates concerning the nutrition of Gibraltarians in the 19th century is, needless to say, sparse at best. We do know, however, that Gibraltar struggled to some degree to maintain its relatively largescale population since its unusual and inhospitable

\footnotetext{
${ }^{3}$ Meaning, careless spitting.
} 


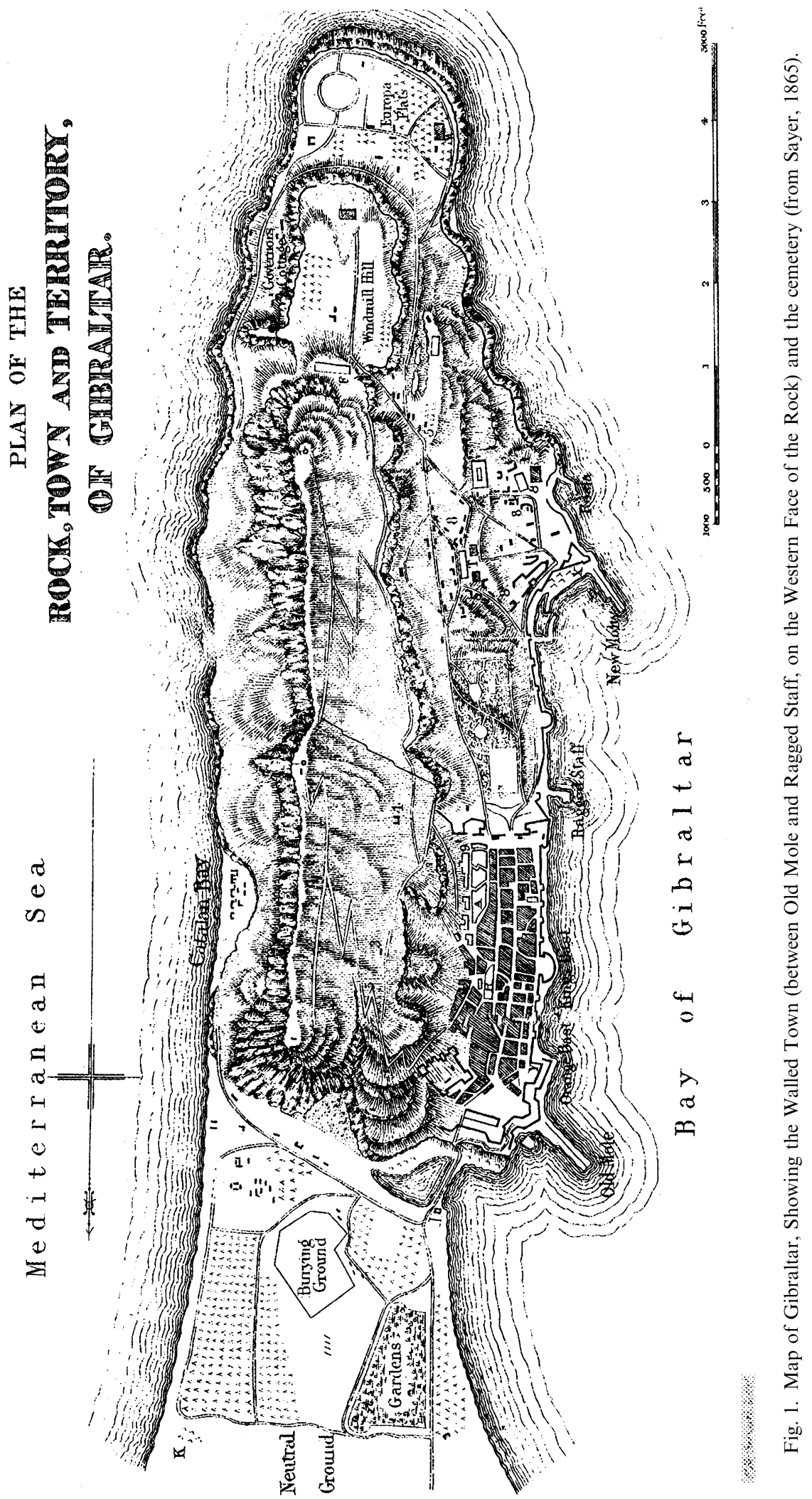


terrain could only provide some dietary necessities. In large part, the provisioning of Gibraltar's population was contingent on good neighborly relations with Spain and Morocco. On a daily basis, Spanish fruit, vegetables, and meats and Moroccan poultry and eggs were brought to Gibraltar's markets. With this "middleman"type of market, it is not surprising that the price of food was dear. According to Hennen (1830), poor Gibraltarians largely relied on "fish, especially salted and dried, pork in its fresh and salted state, macaroni, rice, oil, bread and a large proportion of the leguminous and other vegetables" as their dietary staples. Surveys taken in the early 20th century indicate that the typical diet continued to be largely vegetarian and while sufficient in total caloric intake, it was notably deficient in protein. ${ }^{4}$ An in-depth survey based on 26 working class families taken in 1939 targeted bread as the single most common food item, responsible for some $31 \%$ of the total caloric intake. Bread was also the most important staple of the 19th century and was one of the few food items actually produced in Gibraltar. Sawchuk, Purcell, and Padiak (2001) used the changing price of bread in 19th-century Gibraltar as a key measure to trace fluctuations in the cost of living. The 1939 survey also indicated that protein accounted for only $7.8 \%$ of the total caloric intake. While meat was regarded as more of a luxury item and consumed in small quantities, fish, particularly sardines and shellfish, was a more likely source of protein.

Tuberculosis may have acted as a powerful chronic stressor influencing the well-being of women and threatening the very fabric and viability of the family unit as a whole. Reports from the 19th century indicate that consumptives and their families were often viewed as "pariahs" or social parasites living off the means of others. Not surprisingly, for the poor working-class Gibraltarian struck down by tuberculosis, it was not only "a sentence of death but also... a social stigma and a definite barrier to employment". 5 . The impact of tuberculosis on the family could be particularly harsh as women in Gibraltar seldom worked outside the home and even when forced to under these circumstances, would find little opportunity for gainful employment. Gibraltar's main employers of adult women were the dusty, dirty, and poorly ventilated tobacco chopping factories.

As primary caregivers in the household, women were associated with both the immediate risks of exposure as

\footnotetext{
${ }^{4}$ What is known about the actual diet of Gibraltar's laboring classes comes from information in two reports: a 1906 Public Health Report and a 1939 dietary survey, Gibraltar Government Archives.

${ }^{5}$ Conference proceedings, Gibraltar Colonial Hospital, 22nd March, 1922, involving Drs. Deale, Mansell and Flemming, Gibraltar Government Archives.
}

well as the stress of nursing the ill. Illness was certainly no stranger in 19th-century households, but the tradition of extended family living in Gibraltar clearly increased its potential impact on daily life. According to an analysis of households in the 1878 census, some $29 \%$ of women 15-39 years of age were living with individuals who were 60 years of age and older. This, in concert with the communal nature of patio living, ensured that most women would have experienced illness and dying among those closest to them.

Caring for the tuberculous meant caring for the incurable in 19th-century Gibraltar. Incessant coughing, possibly with hemoptysis (bleeding from the lungs or bronchial tubes), weight loss, fever, night sweats, fatigue, and malaise were typical symptoms of tuberculosis which could inspire feelings of helplessness in a wasting disease. Genuine fear was raised by the specter of its presence in a household. Recent research by Hudelson (1996) provides contemporary evidence that the fear and stigma associated with tuberculosis may have a greater impact on women than on men by virtue of placing them in a more economically or socially precarious position.

\section{The distribution of tuberculosis mortality}

It is clear that over the study period pulmonary tuberculosis ranked as the single-most important cause of adult mortality in Gibraltar. Life table analysis, following the methodology of Chiang (1984) ${ }^{6}$ and using data drawn from cause-specific death registration and the 1878 census (to establish the necessary population at risk of dying), reveals that male and female life expectancy at birth for the period 1874-1884 stood at 34.5 and 40.4 years, respectively. ${ }^{7}$ Alongside period lifeexpectancy estimates, we also use multiple decrement life tables in order to gauge the relative influence of tuberculosis mortality on the population. The multiple decrement approach allows for an empirical assessment of the impact that a specific disease exerted on overall mortality (see Preston, 1976; Preston \& Haines, 1991). In this case, in order to assess the effect of tuberculosis on the community, one can look to the number of potential years that would be added to overall life expectancy if tuberculosis was removed. The multiple decrement life tables indicate that though, on average, women lived longer than men, their tuberculosis burden was slightly higher. Removing tuberculosis as a cause of deaths adds some 3 years to their overall average life expectancy of 40.39 years. Among men, removing tuberculosis meant that an additional 2.5 years would be added to their average life expectancy of 34.52 years.

\footnotetext{
${ }^{6}$ Using the computer software LifePro (Sawchuk \& Anthony, 1989).

${ }^{7}$ Standard errors in life expectancy calculations for males and females are \pm 0.578 and \pm 0.629 , respectively.
} 


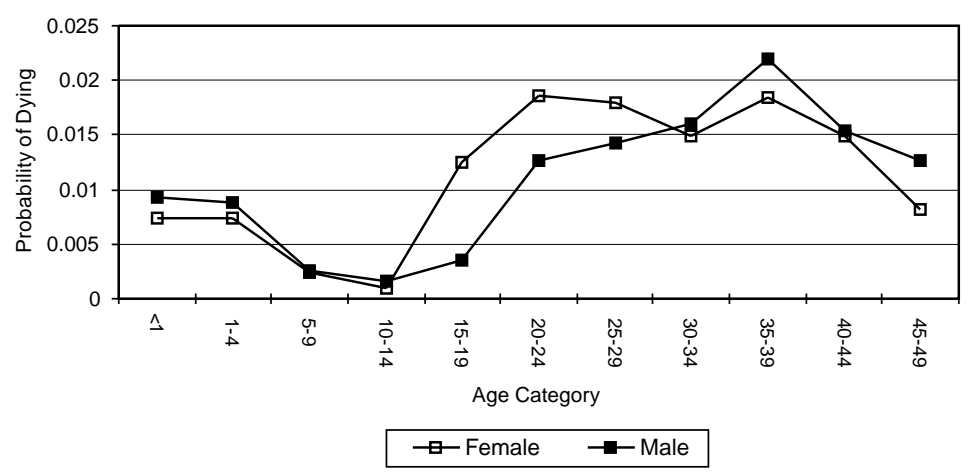

Fig. 2. Age-specific probability of dying from TB, Gibraltar: 1874-1884.

Fig. 2 presents life table-based age-specific probabilities of dying from tuberculosis over the life cycle. ${ }^{8}$ In general, males and females reflect a similar pattern in the risk of tuberculosis mortality over the life span. Outside of early childhood and prior to adulthood, risks of dying from tuberculosis remained relatively low. According to the "golden age" hypothesis, children between 5 and 15 years of age are believed more likely than those in other age groups to present a tuberculosis infection as a minor illness, only to be ravaged by delayed onset of active disease in their adult years (Dubos, 1987). Gibraltarian women's tuberculosis mortality reveals peak risks among women in their reproductive years, beginning with a sharp rise in the 15-19 age group, notably peaking at 20-24 years of age, and followed by slightly lower though still relatively elevated mortality in the 25-29, 30-34, and 35-39 age groups. While mortality also increases markedly among men between the 15-19 and 20-24 year age groups, their overall risks remain lower than those of women. Peak mortality occurs later among men, at 35-39 years of age. These findings are consistent with other studies which have found that young women develop disease sooner after tubercular infection than men (Grzybowski \& Allen, 1964; Springett, 1952).

It is precisely the earlier peak in women's tuberculosis mortality in the reproductive years, as observed here, that has called into question the possible adverse effects of pregnancy and childbirth. According to de March $(1975$, p. 800), there was a strong historical precedent for the interest in the potential "pernicious effect of pregnancy on pulmonary tuberculosis" since women in their maximum reproductive age demonstrated statistically greater mortality burdens and there was an evident "parallelism between the drop in natality and mortality from tuberculosis in women". Historically, in Gibraltar,

\footnotetext{
${ }^{8}$ Analysis was truncated at age 49 in order to minimize haphazard irregularities associated with small numbers of deaths and individuals at risk in the older age categories.
}

women were, for the most part, marrying and beginning childbearing in their early 20s. Could the rise and fall in mortality from tuberculosis be correlated with women's entry into a new phase in their lifecourse?

Differential mortality risks aside, we do know that the constant presence of tuberculosis and the high degree of overcrowding on the Rock ensured that most individuals, male and female alike, would have been infected with the TB bacillus in their youth. According to Ryan (1993, p. 21), "where tuberculosis is common, most of the population will encounter germs when they are children". This pattern of universal susceptibility to infection, which was characteristic of most 19th-century populations, has changed dramatically such that "currently, tuberculosis has retreated into fairly well-defined pockets of high-risk individuals" (Starke, 1997, p. 109). Assuming that most Gibraltarian women were infected by the time they reached adulthood, we question whether the physiological and social strains of recent pregnancy and parturition and early mothering did, in fact, increase the risk of dying from the disease.

\section{Case-control research strategy}

Our research adopts a retrospective case-control study design to evaluate the relationship between recent childbirth and tuberculosis mortality in 19th-century Gibraltar. The sample was drawn from all reproductive age women (15-39 years of age) who died in the years between 1874 and 1884, as determined through entries in the local government death registries. ${ }^{9}$ Name and cause of death was extracted from this source. In the vernacular of the case-control approach, "other deaths" are used here as controls while those dying of tuberculosis serve as our case subjects. By using other deaths as controls, the entire study is conditioned on dying from some cause, so that alternative outcomes

\footnotetext{
${ }^{9}$ An additional year was included in what would have been a 10-year study owing to a partial recording of deaths in 1876 .
} 
(dying from TB, but long after the birth; not dying of anything within the study period) are ruled out. The study design is underpinned by the question of whether, conditional on dying from any cause, recent childbirth increased the chance of that cause of death being tuberculosis.

There are three main reasons for the temporal period we selected in which to situate our case study. First, the fact that tuberculosis was prevalent in Gibraltar, as was the case for most European and, more specifically, Mediterranean communities at the time. High levels of infection led to a large number of individuals dying from this disease, thereby opportunistically allowing for a sufficient sample size in quantitative analyses in this small community. Second, it is important to stress the fact that no effective medical treatments were available at this point in history. As a result, the risk of dying was not influenced by access to or the availability of medical treatment. Finally, there were no major epidemics of infectious disease over the study period. Cholera epidemics, for example, struck the Rock in 1860, 1865, and in 1885 , one year following the close of the study period. The absence of destructive epidemics during the study period ensures a more accurate reflection of the population's everyday mortality burdens brought about by tuberculosis.

Despite the advantages of choosing a 19th-century study period, it is impossible to avoid the potential problem of under-enumerated tuberculosis deaths which comes associated with historical, records-based studies of mortality. Not only could this result from misreporting to the Registrar, or Registrarial error, but also because of the status of medical diagnosis at the time. With a complete absence of any standardized means of identifying individuals suffering from active pulmonary tuberculosis (e.g., sputum samples), diagnosis depended, somewhat crudely, on the presence or absence of symptoms traditionally associated with the disease. Since tuberculosis was a common disease in the late 19th century, however, it is possible that both physicians and lay-persons alike possessed enough familiarity with the disease to aid in its discrimination from other diseases. We cannot, however, rule out the possibility that tuberculosis was implicated as a cause of death when it should not have been, or that it was an unrecognized underlying cause of death which was overshadowed by another more obvious ailment.

\section{Family reconstitution}

The methods of family reconstitution (see Willigan \& Lynch, 1982) were used to link all women (15-39-years of age) listed in death registers between 1874 to 1884 with their reproductive histories and, in particular, the date of their last confinement. In this manner, families are "reconstituted" through linking mothers with their last-born infants, though family reconstitution certainly has broader and larger-scale applications in historic populations (see Galley, 1994; Hionidou, 1998; Kasakoff \& Adams, 2000; Scott, Duncan, \& Duncan, 1995; Rutten, 1993; Wrigley, Davies, Oeppen, \& Schofield, 1997). Stillbirths could present a potential problem in a study of this kind. Following practices in England, stillbirths were not notifiable to the Registrar of Births in 19th-century Gibraltar. Their absence from family reconstitution would result in an under-enumeration of births. Gibraltar offers an unusual opportunity to overcome this caveat. By proclamation, all deceased individuals were obliged to be buried in Gibraltar's one and only cemetery. Stillbirths were recorded in the cemetery register prior to burial. Since we have computerized this register, mother-stillbirth links can be established by family surname and parent's given name. Despite this unusual advantage, the study still cannot account for other unrecognized or otherwise unacknowledged lost pregnancies (e.g., in the first trimester). As a result, our study population of women who were delivered of live- and stillborn infants represents only a potential subset of all pregnancies which occurred among all of the reproductive age women in our sample.

While the sample included both native-born Gibraltarian women and women who were born outside of Gibraltar, the latter group had to have been resident in Gibraltar for at least one full year prior to their death in order to ensure capturing any recent births among immigrant women. ${ }^{10} \mathrm{~A}$ total of ten non-Gibraltarian women were, therefore, removed from the analysis. The remaining sample of reproductive age women who died between 1874 and 1884 was then linked to Gibraltar's births registry. In this case, the card index of births, an alphabetical sorting of births according to parent's surname, was used to yield the date of each women's last liveborn infant, if any. An additional search of the computerized cemetery registry yielded the date of each woman's last stillborn infant, if any.

Since this research is based on family reconstitution and vital-events registration, it is important to highlight the quality of record-keeping in Gibraltar during the 19 th century. According to colonial policies at the time, paramount importance was placed on the strict recording of all vital events pertaining to the civilian community. Colonial authorities were particularly concerned with any appreciable growth in the size of the civilian community, with the attendant risks that would be placed on the health, functioning, and security of the military forces stationed on the Rock. Vital-events

\footnotetext{
${ }^{10}$ This requirement also had the effect of excluding alien women on the Rock under temporary employment-related premises since they had to leave Gibraltar for at least one day each year to renew their work permits.
} 
linkages are further facilitated by the fact that Gibraltar was characterized by particularly low levels of emigration in the 19th century. As a result, there is an increased likelihood of finding women in multiple demographic sources (births and deaths registries).

While the record-linkage provided us with each woman's recent reproductive history, the death registrations supplied us with their age at death, marital status, and religion (and cause of death, as outlined earlier). In this study, religion serves as both an economic and cultural indictor with important underlying implications for health, disease, and, ultimately, mortality. In historical populations, it is occupation that is traditionally factored in as a proxy for social class. Studies focusing on women typically suffer problems in determining social class as many women were absent from the paid labor force; reliance on husband's occupation has traditionally served as a reasonable but problematic proxy for class among women. Even this surrogate measure was not useful in the current study, however, since only a fraction of women in the sample were married at the time of death. As a result, we employ another measure for social class, namely religion, which is relevant to Gibraltar and relates directly to its colonial origins. Anglicans, drawn mainly from England to hold positions of authority or prestige in the colony, and Jews, the majority of whom were merchants and

Table 1

Presence of a servant in households according to religious affiliation of the head of household: 1878

\begin{tabular}{lll}
\hline Household head & $\begin{array}{l}\text { No servant } \\
\text { number } \\
\text { (Residual) }\end{array}$ & $\begin{array}{l}\text { Servant number } \\
\text { (Residual) }\end{array}$ \\
\hline Jewish & $226(-7.0)$ & $85(7.0)$ \\
Protestant & $253(-5.9)$ & $83(5.9)$ \\
Roman Catholic & $2845(9.5)$ & $376(-9.5)$ \\
\hline
\end{tabular}

selectively admitted to strengthen the isolated colony's trade links in the Mediterranean, were typically overrepresented in Gibraltar's upper social classes. The Roman Catholic population was, for the most part, of local Mediterranean origin and represented more of the colony's working class. According to the 1878 census, Roman Catholics were the most numerically common religious group on the Rock ( $84.7 \%$ of the population), followed by Jews $(8.3 \%)$, Protestants $(6.7 \%)$, and "other" groups $(0.3 \%)$.

An analysis of the heads of households located in the 1878 census confirms that there was a statistically significant association between wealth (as measured by the presence of a live-in servant) and religious affiliation $\left(X^{2}=78.81, \mathrm{df}=2, p<0.0005\right)$. Closer inspection of Table 1 reveals that Roman Catholic headed households had significantly fewer servants than expected (note the adjusted standardized residual of -9.5). A further analysis of crowding among married couples under the age of 50 who were heading households at the time of the 1891 census reveals that Jewish households were less crowded (mean $=1.70$ persons per room, $n=53$ ) than non-Jewish households (mean $=2.39$ persons per room, $n=437$ ). An analysis of variance confirms that, after controlling for the effects of both age and wealth (as measured by the presence of a servant), Jewish households were significantly less crowded than those of their non-Jewish counterparts (see Table 2). This finding, that crowding is associated with religion more so than with social status (indicated by servants), highlights another important aspect of religion-beyond simply serving as a reference point for social class, religion also had specific cultural implications unto itself. As a case in point, it has been argued by Sawchuk, Herring, and Waks (1985) that the health of Jewish infants in 19thcentury Gibraltar fared substantially better than that of their Gentile counterparts owing to cultural traditions grounded in mosaic-Talmudic hygienic rituals encouraging personal and domestic hygiene and favoring the maintenance of well-ordered households.

Table 2

Analysis of variance modeling crowding by age, religion, and wealth

\begin{tabular}{|c|c|c|c|c|c|}
\hline Source & Type III sum of squares & df & Mean square & $\mathrm{F}$ & Sig. \\
\hline Corrected model & $60.935^{\mathrm{a}}$ & 4 & 15.234 & 10.142 & $<0.001$ \\
\hline Intercept & 28.480 & 1 & 28.480 & 18.961 & $<0.001$ \\
\hline Age & 3.716 & 1 & 3.716 & 2.474 & 0.116 \\
\hline Jewish & 7.247 & 1 & 7.247 & 4.825 & 0.029 \\
\hline Servant & 11.930 & 1 & 11.930 & 7.943 & 0.005 \\
\hline Jewish*Servant & 2.022 & 1 & 2.022 & 1.346 & 0.246 \\
\hline Error & 728.463 & 485 & 1.502 & & \\
\hline Total & 3421.131 & 490 & & & \\
\hline Corrected total & 789.398 & 489 & & & \\
\hline
\end{tabular}

\footnotetext{
${ }^{\mathrm{a}} R^{2}=0.077$ (Adjusted $R^{2}=0.070$ ).
} 


\section{Logistic regression}

Logistic regression is the most naturally suited statistic for our case-control study since it allows for the prediction of a bivariate categorical dependent variable (TB death, non-TB death) and, as a multivariate statistic, it allows us to include other confounding variables (age, martial status, religion) in the analysis (see Hosmer \& Lemeshow, 1989). The independent variables and their codings included recent birth ("birth within 1 year of death" or "no birth within 1 year of death"), age (in 5-year intervals), marital status (never married, married, or widowed), and religion (Roman Catholic, Jewish, or Anglican). The aims of the regression modeling are modest, simply allowing us to test the significance of one factor (recent childbirth), while factoring in the effects of other important explanatory variables. The model is not intended to provide a comprehensive assessment of the determinants of tuberculosis mortality in 19th-century Gibraltar. In part, because it was not the intention of the study and, in part, because of the limited nature of the data collected. There is no question that a stronger model predicting for TB mortality would take into account other important factors such as nutrition, working conditions, and household crowding. As a result, the ambitions of the regression model may be modest, yet they are highly focused to evaluate the significance of recent childbirth on TB mortality among reproductive age women.

One important caveat inherent in the data is the strong link between recent childbirth and non-tuberculosis deaths which is produced by maternal deaths. Thirty cases of strictly defined "maternal deaths" (i.e., deaths within 42 days of birth of pregnancy-related causes: puerperal pyrexia, febris puerperal, post-partum hemorrhage, parturition, abortion) were removed from the sample owing to the strong relationship which is otherwise established between recent pregnancy and non-tuberculosis deaths in the logistic regression model. In other words, because of the overwhelmingly positive correlation which exists between birth within one year and maternal (non-TB) deaths, the results, not surprisingly, simply point to a highly significant correlation between recent birth and non-TB deaths. The strength of this association essentially overpowers any possibly less salient effects of recent childbirth on TB deaths. This is a problem which cannot be overcome, other than by dropping the 30 maternal deaths from analysis and accepting the slightly shifted "true" relationship between cause of death and recent childbirth. Despite the removal of these strictly defined maternal cases, there remained eight deaths in that 42-day period which were retained in the sample since cause of death was neither directly pregnancy- nor confinement-related (3 tuberculosis, 1 pneumonia, 2 pulmonary congestion, 1 cerebral fever, and 1 cerebral apoplexy).
Table 3

Sample descriptives of reproductive-age Gibraltarian women who died between 1874 and 1884

\begin{tabular}{ll}
\hline Factor & $N(\%)$ \\
\hline Cause of death & \\
Non-TB death & $108(44.3)$ \\
TB death & $136(55.7)$ \\
Birth within 1-year & \\
No & $215(88.1)$ \\
Yes & $29(11.9)$ \\
Age & \\
$15-19$ & $39(16.0)$ \\
$20-24$ & $51(20.9)$ \\
$25-29$ & $61(25.0)$ \\
$30-34$ & $41(16.8)$ \\
$35-39$ & $52(21.3)$ \\
Marital status & $125(51.2)$ \\
Never married & $105(43.0)$ \\
Married & $14(5.7)$ \\
Widowed & $17(7.0)$ \\
Religion & $210(86.1)$ \\
Jewish & $17(7.0)$ \\
Roman Catholic & \\
Anglican &
\end{tabular}

\section{Sample descriptives}

Sample descriptives for the 244 women in our study are outlined in Table 3 . The majority of the reproductive age women in this sample, some $55.7 \%$, died of pulmonary tuberculosis. The record linkage indicates that almost $12 \%$ of the women in our sample had given birth within the year preceding their death, an estimate which would have been higher still had we also considered the maternal deaths in this calculation. This finding also reveals another important issue - the large number of Gibraltarian infants left motherless in their first year of life. More than half of those infants lost their mothers to tuberculosis (Table 4). Still, this important social issue maintains a hold on developing countries today where, along with AIDS, "many orphans also are being created by tuberculosis" (Starke, 1997 , p. 108). Of the other explanatory variables collected from the record linkage, age was fairly evenly distributed across the age groups between 15 and 39, and most of the women in the sample were either never married $(51.2 \%)$ or married $(43.0 \%)$ (Table 3$)$. The large proportion of unmarried women is not unexpected since the mean age at marriage for women between 1866 and 1890 was calculated at 24 years (see Table 5). It is also important to bear in mind that since this is a sample of women who died fairly early in life, even by 19th-century standards, there may have been any number of factors mitigating their decision or ability to enter into marriage, including their general health or economic 
Table 4

Causes of death among women in the sample

\begin{tabular}{|c|c|c|}
\hline Cause of death & $\begin{array}{l}\text { Death within } \\
1 \text { year of } \\
\text { giving birth }\end{array}$ & $\begin{array}{l}\text { All other } \\
\text { deaths }\end{array}$ \\
\hline Anemia/Blood-related ${ }^{\mathrm{a}}$ & 1 & 6 \\
\hline Brain-related $^{\mathrm{b}}$ & 1 & 7 \\
\hline Cancer $^{\mathrm{c}}$ & 1 & 4 \\
\hline Cardiovascular-related $^{\mathrm{d}}$ & & 24 \\
\hline Diabetes & & 1 \\
\hline Fevers \& Convulsions ${ }^{\mathrm{e}}$ & 3 & 23 \\
\hline Gastroenteritis & & 2 \\
\hline Inflammations ${ }^{\mathrm{f}}$ & & 4 \\
\hline Kidney-related $^{\mathrm{g}}$ & & 2 \\
\hline Liver-related $^{\mathrm{h}}$ & & 3 \\
\hline Lung-related $^{\mathrm{i}}$ & 6 & 15 \\
\hline Smallpox & & 2 \\
\hline Other $^{\mathrm{j}}$ & & 3 \\
\hline Total & $12(41.4 \%)$ & $97(45.1 \%)$ \\
\hline $\begin{array}{l}\text { Pulmonary } \\
\text { consumption }\end{array}$ & 5 & 34 \\
\hline Phthisis & 12 & 84 \\
\hline Total & $17(58.6 \%)$ & $118(54.9 \%)$ \\
\hline
\end{tabular}

${ }^{a}$ Including: anemia, anemia cerebral, chlorosis anascarca, cloroanemia, leucocythemia.

${ }^{b}$ Including: acute encephalitis, apoplexia cerebralis, brain inflammation/softening/tumour, cerebral congestion, meningitis.

${ }^{\mathrm{c}}$ Including: cancer, necrosis, ovarian tumour.

dincluding: hydropericarditis, apoplexy, carditis, dropsy, heart degeneration/dilatation/disease, mitral valve disease, pericarditis, syncope.

${ }^{\mathrm{e}}$ Including: adanamic fever, ataxic fever, bilious fever, enteric fever, fever, gastric fever, hectic fever, remittent fever, simple chronic fever, typhoid fever, typhus fever, convulsions.

${ }^{\mathrm{f}}$ Including: metritis, peritonitis, and erysipelas.

${ }^{\mathrm{g}}$ Including: addisons disease, brights disease.

${ }^{\mathrm{h}}$ Including: hepatitis, liver abcess/hypertrophy.

${ }^{\mathrm{i}}$ Including: asthma, bronchitis, lung disease, pleuropneumonia, pneumonia, pulmonary catarrh.

${ }^{\mathrm{j}}$ Including: general paralysis, acute mania, morbus cordis.

Table 5

Age at first marriage among Roman Catholic couples, Gibraltar: 1866-1890

\begin{tabular}{lrrrrr}
\hline & \multicolumn{2}{c}{ Male } & & & \multicolumn{2}{c}{ Female } \\
\cline { 2 - 3 } \cline { 6 - 7 } & \multicolumn{1}{c}{$N$} & \multicolumn{1}{c}{$\%$} & & $n$ & $\%$ \\
\hline Under 20 & 97 & 3.4 & & 793 & 26.9 \\
$20-24$ & 1026 & 35.7 & & 112 & 38.1 \\
$25-29$ & 928 & 32.3 & & 572 & 19.4 \\
$30-34$ & 421 & 14.7 & & 207 & 7.0 \\
$35-39$ & 185 & 6.4 & & 116 & 3.7 \\
40 plus & 214 & 7.5 & & 137 & 4.7 \\
Mean age (yrs) & 27.9 & & & & \\
\hline
\end{tabular}

status. In keeping with what is known of the colony's demographics, Roman Catholic women made up the majority $(86 \%)$ of the sample.

\section{Issue of selectivity}

Underpinning the analysis and results, we must also mention the important issue of selectivity in our sample. In their study of maternal mortality in Bangladesh, Khlat and Ronsmans (2000, p. 305) recognize that "... women suffering from disabilities or chronic diseases will be less likely to become pregnant because of behavioral or biologic causes, and they may be underrepresented among pregnant women". If tuberculosis disease influenced either fecundity or fertility in 19thcentury Gibraltar, this issue must be addressed. Even more directly, tuberculosis disease could have also influenced nuptiality, or the opportunities or desires for tuberculous women to marry. In this community, the link between marriage and childbearing was quite strong and is born out by the observation that none of the never-married women in this sample could be linked with any previous births. If tuberculosis disease did, indeed, influence nuptiality, fecundity, or fertility, then our analysis addressing recent childbirth and tuberculosis mortality could hinge on a biased sample. In other words, we may be capturing only those "healthier" tuberculous women whose opportunities for marriage and childbearing were not affected by their disease. If this were the case, we might expect that women who died of TB would be less likely to have been married or to have experienced childbirth. A $\chi^{2}$ analysis of our data indicates that there were no significant differences in the proportion of women married among those who had died of TB and those who had died of other causes $\left(54.4 \%\right.$ and $50.9 \%$, respectively, $\chi^{2}=0.342, \quad 1 \mathrm{df}$, $p=0.559)$. We also considered the proportion of women who had registered births (versus those who had never registered any births) among those who died of TB $(76.7 \%)$ and those who died of other causes $(69.5 \%)$ and, once again, no significant differences emerged $\left(\chi^{2}=0.952\right.$, $\left.1 \mathrm{df}, p=0.329\right)$. To conclude, therefore, while our sample may, indeed, still retain some "healthy tuberculous woman" bias among those who had experienced recent childbirth, the data do suggest that women who died of TB were not more likely than women who died of other causes to have remained either spinsters or childless.

\section{Results and discussion}

The logistic regression model predicting for tuberculosis mortality among women of reproductive age includes the effects of birth status within one year of dying, age at death, religion, and marital status 
Table 6

Logistic regression results predicting for tuberculosis deaths among reproductive-age Gibraltarian women, 1874-1884

\begin{tabular}{|c|c|c|c|c|}
\hline Factor & $\begin{array}{l}\text { Model } 1 B(\mathrm{SE}) \\
{[\operatorname{Exp}(B)]}\end{array}$ & $\begin{array}{l}\text { Model } 2 B(\mathrm{SE}) \\
{[\operatorname{Exp}(B)]}\end{array}$ & $\begin{array}{l}\text { Model } 3 B(\mathrm{SE}) \\
{[\operatorname{Exp}(B)]}\end{array}$ & $\begin{array}{l}\text { Model } 4 B(\mathrm{SE}) \\
{[\operatorname{Exp}(B)]}\end{array}$ \\
\hline \multicolumn{5}{|l|}{$\begin{array}{l}\text { Birth within 1-year } \\
\mathrm{No}^{\mathrm{R}}\end{array}$} \\
\hline Yes & $0.134(0.401)$ & $-0.091(0.424)$ & $-0.219(0.423)$ & $-0.426(0.479)$ \\
\hline $\begin{array}{l}\text { Age } \\
\qquad 15-19^{\mathrm{R}}\end{array}$ & & & & \\
\hline $\begin{array}{l}20-24 \\
25-29 \\
30-34 \\
35-39\end{array}$ & & $\begin{array}{l}1.248(0.468)[3.484 * *] \\
0.297(0.417) \\
0.014(0.450) \\
-0.096(0.426)\end{array}$ & $\begin{array}{l}1.442(0.487)[4.228 * *] \\
0.317(0.422) \\
0.006(0.455) \\
-0.050(0.432)\end{array}$ & $\begin{array}{l}1.302(0.488)\left[3.676^{* *}\right] \\
-0.009(0.455) \\
-0.404(0.502) \\
-0.553(0.490)\end{array}$ \\
\hline \multicolumn{5}{|l|}{ Jewish ${ }^{\mathrm{R}}$} \\
\hline $\begin{array}{l}\text { Roman Catholic } \\
\text { Anglican }\end{array}$ & & & $\begin{array}{l}1.323(0.577)\left[3.755^{*}\right] \\
1.213(0.755)\end{array}$ & $\begin{array}{l}1.113(0.587)[3.044 *] \\
1.016(0.766)\end{array}$ \\
\hline \multicolumn{5}{|l|}{ Marital Status } \\
\hline $\begin{array}{l}\text { Married } \\
\text { Widowed }\end{array}$ & & & & $\begin{array}{l}0.539(0.354) \\
2.086(0.823)\left[8.056^{* *}\right]\end{array}$ \\
\hline $\begin{array}{l}-2 \text { Log likelihood } \\
\text { Model } \chi^{2}\end{array}$ & $\begin{array}{l}334.924 \\
\chi^{2}=0.111, \mathrm{df}=1, \\
p=0.739\end{array}$ & $\begin{array}{l}321.996 \\
\chi^{2}=13.039 \\
d f=5, p=0.023\end{array}$ & $\begin{array}{l}316.308 \\
\chi^{2}=18.728, d f=7 \\
p=0.009\end{array}$ & $\begin{array}{l}307.246 \\
\chi^{2}=27.790, d f=9 \\
p=0.001\end{array}$ \\
\hline
\end{tabular}

${ }^{*} p \leqslant 0.05 ; * * \leqslant \leqslant 0.01$

(Table 6). Most importantly, for the purposes of this study, recent childbirth is not a significant predictor for tuberculosis mortality among this sample of reproductive age women who all died in the years between 1874 and 1884. So, in other words, all else being equal, women who had recently given birth were not significantly more likely to have died from tuberculosis than any other cause of death. Though the statistics are not presented here, recent birth continues to be a poor (i.e., non-significant) predictor for tuberculosis mortality even when the interval between birth and death is extended to two years, in an attempt to capture more extended social and physiologic strains associated with young child care. ${ }^{11}$ Two immediate possibilities may be considered in interpreting these regression results. First, it is possible that recent childbirth impacted equally on dying from any cause, tuberculosis or non-tuberculosis (e.g., cardiovascular causes of death; fevers and convulsions outside of the immediate post-partum period), in effect generally increasing the risk of death among reproductive-age women. Alternatively, recent childbirth may have exerted no significant impact at all on either tuberculosis or non-tuberculosis mortality. In other words, outside of the obvious link between recent childbirth and maternal deaths, recent confinement may have generally increased the risk of dying in an across-

\footnotetext{
${ }^{11}$ Of the 244 women in the sample, some $21.3 \%(n=52)$ had given birth within the two years prior to their death.
}

the-board manner among reproductive-age women or may really have posed no threats to survival, either through the tuberculosis or non-tuberculosis deaths which claims the lives of these women. This is a matter which remains to be resolved, though it is clear that in this sample recent childbirth was not significantly associated with dying from tuberculosis.

Outside of recent childbirth, age at death, religion, and marital status did prove to be significant explanatory variables in this model. Among women in 19thcentury Gibraltar, and in keeping with the pace of female mortality outlined earlier in Fig. 2, the odds of dying from tuberculosis rise sharply between the teenage and young adult years and taper off again after age 25 . This classic pattern of tuberculosis mortality indicates that young adult women were most susceptible to dying from this infectious disease. Relative to women 15-19 years of age, the odds were almost four to one that a women 20-24 years of age would die of tuberculosis, even when taking into account her recent reproductive history, marital status, and religion.

After controlling for age and the other independent factors, marital status also figures prominently in predicting for tuberculosis mortality. The regression indicates that, relative to never married women, the odds of dying from tuberculosis rise to eight to one among widowed women. There are, however, no significant differences in tuberculosis mortality between married women and women who had never married. The 
findings of a heightened risk of dying from tuberculosis among widows leads us to offer at least two reasonable alternative explanations, both of which will require further scrutiny. First, there is the possibility that the deceased husbands of widowed women were, themselves, struck down by tuberculosis. Living in close proximity to sick husbands and possibly caring for them over the course of their illness could have compromised the health of the women who were eventually left widowed by the death of their spouse. A examination of husband's cause of death, however, does not seem to support this possibility. Alternatively, having lost their husbands, widows may have found themselves living under less supportive circumstances prior to their own death. Being widowed, and having to overcome increased financial and emotional stress, tuberculosis may have been given the opportunity to take hold. A study of tuberculosis reactivation among individuals living in New York City in 1967 suggested that "the tuberculous disease in a patient has a better chance of staying inactive in a family environment where relatives are concerned about the patient's well-being" (Edsall et al., 1970, p. 734).

Religion, though only marginally significant ( $p=0.05$ ), suggests that the social class and cultural differences distinguishing Anglicans, Jews, and Roman Catholics in the 19th century had important implications for tuberculosis mortality. Relative to the referent group of Jewish women, the odds were three to one that Roman Catholic women would die from tuberculosis. No significant differences in tuberculosis mortality were noted between Jewish and Anglican women. The findings on religion are largely supported by what is known of tuberculosis mortality patterns among infants in Gibraltar's three main religious groups and the social hierarchy which distinguished them (Sawchuk \& Herring, 1984). Access to scarce resources on the barren Rock among the higher classes and beneficial religiously grounded perspectives on health and disease among Gibraltar's Jewish population could have buffered both Anglicans and Jews either from tuberculosis infection or, more likely, the manifestation of the disease following infection. In Gibraltar, there were no Poor Laws and the civilian inhabitants were dependent on their relatives, neighbors and co-religionists in times of need. The Sephardic tradition of health care in Gibraltar, with its pattern of hierarchical welfare and positive attitude to helping the poor, sick, and aged, may have played a role in lessening the impact of tuberculosis in the Hebrew community (Sawchuk \& Herring, 1984). A case in point is illustrated by the establishment of a specific charity for the sick when it was rumored that an old Jew had died from lack of care and the want of food,

The Jews considered this a hillul aschem, a disgrace to the community, as a lash of a whip across the face and a blot of ignominy that fell over one and all and one which it was necessary to take possible steps to avoid its repetition (Serfaty 1958, p. 30).

While there were similar charities established for Roman Catholics, the greater number of poor and the proportionately lower economic base meant that they were less likely to be able to offer equitable financial and social support than was available to Jewish inhabitants of the Rock.

\section{Conclusion}

It is clear from this analysis that recent pregnancy, parturition and young childcare, elements of women's lives laying the groundwork for both gender- and sexrelated strains, did not account for any heightened odds of dying from tuberculosis. The simple act of having had a child did not increase the risk of dying from this disease among reproductive-age women, at least not during the 11 years of our late 19th-century Gibraltar sample. A more detailed analysis of reproductive histories based on a re-defined cohort of child-bearing (as opposed to the more general "reproductive age") women, focusing on the total number of children and the spacing of pregnancies, may implicate pregnancy risks at a more detailed level. Lerner (1994, p. 368), for example, found that early 20th-century "authors frequently paraphrased the teaching of DuBois, who had stated that a woman with tuberculosis 'bear[s] the first [pregnancy] well, a second with difficulty, [and] a third never"'. Larger scale social- and gender-related influences on the timing, spacing, and total number of children distinguishing women's reproductive histories in historic populations may have been more important to the risk of dying from tuberculosis than the narrower physiologic and social manifestations of a recent pregnancy.

\section{Acknowledgements}

The authors wish to thank the journal's anonymous reviewers for their valuable and insightful comments which substantially improved the final manuscript. This work was supported by research funding from the Social Science and Humanities Research Council of Canada.

\section{References}

Anderson, G. D. (1997). Tuberculosis in pregnancy. Seminars in Perinatology, 21, 328-335. 
Balasubramanian, V., Wiegeshaus, E. H., \& Smith, D. W. (1994). Pathogenesis of tuberculosis: Pathway to apical localization. Tubercle and Lung Disease, 75, 168-178.

Blackwell, J. M. (1998). Genetics of host resistance and susceptibility to intramacrophage pathogens: A study of multi-case families of tuberculosis, leprosy and leishmaniasis in north-eastern Brazil. International Journal for Parasitology, 28, 21-28.

Bloom, B. R., \& Small, P. M. (1998). The evolving relation between humans and mycobacterium tuberculosis. New England Journal of Medicine, 338, 677-678.

Chiang, C. (1984). The life table and its applications. Malabar: Krieger Publishing Co.

DeRiemer, K., Chin, D. P., Schecter, G. F., \& Reingold, A. L. (1998). Tuberculosis among immigrants and refugees. Archives of Internal Medicine, 158, 753-760.

Diwan, V. K., \& Thorson, A. (1999). Sex, Gender, and Tuberculosis. Lancet, 353, 1000-1001.

Dolin, P. J., Raviglione, M. C., \& Kochi, A. (1994). Global tuberculosis incidence and mortality during 1990-2000. Bulletin of the World Health Organization, 72, 213-220.

Dubos, R. J. (1987). The white plague: Tuberculosis, man, and society. New Brunswick: Rutgers University Press.

Edsall, J., Collins, J. G., \& Gray, J. A. C. (1970). The reactivation of tuberculosis in New York City in 1967. American Review of Respiratory Disease, 102, 725-736.

Elender, F., Bentham, G., \& Langford, I. (1998). Tuberculosis mortality in England and Wales during 1982-1992: Its association with poverty, ethnicity and aids. Social Science and Medicine, 46, 673-681.

Espinal, M. A., Reingold, A. L., \& Lavandera, M. (1996). Effect of pregnancy on the risk of developing active tuberculosis. Journal of Infectious Diseases, 173, 488-491.

Galley, C. (1994). A never-ending succession of epidemicsmortality in early modern York. Social History of Medicine, 7, 29-57.

Good, J. T., Iseman, M. D., Davidson, P. T., Lakshminarayan, S., \& Sahn, S. A. (1981). Tuberculosis in association with pregnancy. American Journal of Obstetrics and Gynecology, 140, 492-498.

Grzybowski, S., \& Allen, E. A. (1964). The challenge of tuberculosis in decline: A study based on the epidemiology of tuberculosis in Ontario. American Review of Respiratory Disease, 90, 707-720.

Hamadeh, M. A., \& Glassroth, J. (1992). Tuberculosis and pregnancy. Chest, 101, 1114-1120.

Hedvall, E. (1953). Pregnancy and tuberculosis. Acta Medica Scandinavica, 147(Suppl. 2), 1-101.

Hennen, J. (1830). Sketches of the medical topography of the Mediterranean comprising an account of Gibraltar, the Ionian Islands, and Malta; to which is prefixed, a sketch of a plan for memoirs on medical topography. London: Thomas and George Underwood, Fleet Street.

Hionidou, V. (1998). The adoption of fertility control on Mykonos, 1879-1959: Stopping, spacing or both? Population Studies, 52, 67-83.

Horrocks, W. H. (1904). Annual report on the public health of Gibraltar for the year 1903 (p. 7.). Gibraltar: Gibraltar Garrison Printing.

Hosmer, D. W., \& Lemeshow, S. (1989). Applied logistic regression. New York: Wiley.
Hudelson, P. (1996). Gender differentials in tuberculosis: The role of socio-economic and cultural factors. Tubercle and Lung Disease, 77, 391-400.

Kasakoff, A. B., \& Adams, J. W. (2000). The effects of migration, place, and occupation on adult mortality in the American North, 1740-1880. Historical Methods, 33, $115-130$.

Khlat, M., \& Ronsmans, C. (2000). Deaths attributable to childbearing in Matlab, Bangladesh: Indirect causes of maternal mortality questioned. American Journal of Epidemiology, 151, 300-306.

Lerner, B. H. (1994). Constructing medical indications: The sterilization of women with heart disease or tuberculosis, 1905-1935. Journal of the History of Medicine and Allied Sciences, 49, 362-379.

de March, P. (1975). Tuberculosis and pregnancy: Five- to ten-year review of 215 patients in the fertile age. Chest, 68 , 800-804.

McMurray, D. N. (1998). Impact of nutritional deficiencies on resistance to experimental pulmonary tuberculosis. Nutrition Reviews, 56, S147-S152.

Medical Officer of Health (1893). Annual report on the public health of Gibraltar for the year 1892 (p. 8). Gibraltar: Gibraltar Garrison Printing.

Miller, K. S., \& Miller, J. M. (1996). Tuberculosis in pregnancy: Interactions, diagnosis, and management. Clinical Obstetrics and Gynecology, 39, 120-142.

Mitchinson, W. (1991). The nature of their bodies: Women and their doctors in victorian Canada. Toronto: University of Toronto Press.

Mizrahi, V. (1997). Genetics and tuberculosis, Cape Town, South Africa, 21 November 1997. Tubercle and Lung Disease, 78, 171-174.

Pospelov, L. E., Matrakshin, A. G., \& Chernousova, L. N., et al. (1996). Association of various genetic markers with tuberculosis and other lung diseases in Tuvinian children. Tubercle and Lung Disease, 77, 77-80.

Preston, S. H. (1976). Mortality patterns in national populations. New York: Academic Press.

Preston, S. H., \& Haines, M. R. (1991). Fatal years: Child mortality in late nineteenth-century America. Princeton: Princeton University Press.

Raviglione, M. C., Sudre, P., \& Rieder, H. L., et al. (1993). Secular trends of tuberculosis in Western Europe. Bulletin of the World Health Organization, 71, 297-306.

Rosenbach, L. M., \& Gangemi, C. R. (1956). Tuberculosis and pregnancy. Journal of the American Medical Association, 161, 1035-1038.

Rutten, W. (1993). Smallpox, subfecundity, and sterility-a case-study from a nineteenth century Dutch municipality. Social History of Medicine, 6, 85-99.

Ryan, F. (1993). The forgotten plague: How the battle against tuberculosis was won- and lost. Boston: Little, Brown and Company.

Sawchuk, L. A. (1993). Societal and ecological determinants of urban health: A case study of pre-reproductive mortality in nineteenth century Gibraltar. Social Science and Medicine, $36,875-892$.

Sawchuk, L. A., \& Anthony, A. (1989). Lifepro: A computerised life table program. Scarborough, Ontario: Population Research Software. 
Sawchuk, L. A., \& Herring, D. A. (1984). Respiratory tuberculosis mortality among the Sephardic Jews of Gibraltar. Human Biology, 56, 291-306.

Sawchuk, L. A., Herring, D. A., \& Waks, L. R. (1985). Evidence of a Jewish advantage: A study of infant mortality in Gibraltar, 1870-1959. American Anthropologist, 87, 616-625.

Sawchuk, L. A., Purcell, J., \& Padiak, J. (2001). Military and civilian suicides in early twentieth century Gibraltar. Paper presented at the Hannah International Conference on the History of Mental Illness, University of Toronto \& McMaster University, Ontario, Canada, April 17-18, 2001

Sayer, F. (1865). The history of Gibraltar and of its political relation to events in Europe. London: Chapman and Hall.

Schaefer, G., Zervoudakis, I. A., Fuchs, F. F., \& David, S. (1975). Pregnancy and pulmonary tuberculosis. Obstetrics and Gynecology, 46, 706-715.

Scott, S., Duncan, S. R., \& Duncan, C. J. (1995). Infantmortality and famine - a study in historical epidemiology in Northern England. Journal of Epidemiology and Community Health, 49, 245-252.

Serfaty, A. B. M. (1958). The Jews of Gibraltar under British rule. Gibraltar: Garrison Library Printing Works.
Skamene, E. (1989). Genetic control of susceptibility to mycobacterial infections. Reviews of Infectious Diseases, 11, S394-S399.

Smith, F. B. (1988). The retreat of tuberculosis, 1850-1950. London: Croom Helm.

Snider, D. (1984). Pregnancy and tuberculosis. Chest, 86, 10S-13S.

Springett, V. H. (1952). An interpretation of statistical trends in tuberculosis. Lancet, 262, 521-580.

Starke, J. R. (1997). Tuberculosis: An old disease but a new threat to the mother, fetus, and neonate. Infections in Perinatology, 24, 107-127.

Stokes, H. (1880). Public Health of Gibraltar, 1879. Gibraltar Chronicle 85 (13161), Tuesday April 15.

Walker, P. L., \& Cook, D. C. (1998). Brief communication: Gender and sex: Vive la difference. American Journal of Physical Anthropology, 106, 255-259.

Willigan, J. D., \& Lynch, K. A. (1982). Sources and methods of historical demography. New York: Academic Press.

Wilson, E. A., Thelin, T. J., \& Dilts, P. V. (1973). Tuberculosis complicated by pregnancy. American Journal of Obstetrics and Gynecology, 115, 526-529.

Wrigley, E. A., Davies, R. S., Oeppen, J. E., \& Schofield, R. S. (1997). English population history from family reconstitution, 1580-1837. Cambridge: Cambridge University Press. 